\title{
Explanatory Basis of Metaphysics and the Prospect for a Complete Description of Everything that Exists
}

\author{
Aleksandr Kulieshov ${ }^{1}$ \\ ${ }^{1}$ Cherkasy State Technological University \\ 460 Shevchenko Boulevard, 18006, Cherkasy, Ukraine
}

DOI: $10.22178 /$ pos.60-1

LCC Subject Category: BD95-131

Received 20.06.2020

Accepted 27.07.2020

Published online 31.07.2020

Corresponding Author:

klshv2014@gmail.com

(c) 2020 The Author. This article is licensed under a Creative Commons Attribution 4.0 License @) (1)

\begin{abstract}
The article deals with the problem concerning the principles of the metaphysics explanatory basis, which provide the achievement of the goals in this most general, most abstract, and, at the same time, the most debatable field of knowledge. Different kinds of explanatory basis in metaphysics are analyzed - cosmic mereological monism, structural cosmic monism, cosmic modal monism, natural substance monism, transcendent substance monism, existential monism, abstract monism as well as the similar kinds of metaphysical pluralism including atomism and space-time pluralism. The implausibility of pluralism and its inefficiency for solving the problems of metaphysics is argued, while for metaphysical monism the need for its clarification as a grounding force is stated. The conception of super-monism is proposed. It is based on the logic of fundamental reality which differs from generally accepted formal logic in that it lacks logical laws, primarily the law of contradiction. The fundamental reality is defined as pure being which is identical with a difference, identity, existence, and the existing. By the identification of the various, this reality is defined as one. By identity with distinction, this reality is defined as the ground of all world diversity. Being which is expressed in terms of difference and identity is reflected in the metaphysical formula, which is proposed as the only tool for describing everything that exists at the extremely abstract level.
\end{abstract}

Keywords: metaphysics; explanatory basis; metaphysical monism; metaphysical pluralism; super-monism; the logic of fundamental reality; difference; identity; the basic formula of metaphysics.

\section{INTRODUCTION}

Any science seeks to explain the maximum of objects within its subject area using the minimum of explanatory tools - terms and statements which correspond to a certain basic area within the subject area of this science. Such a basic area can be called the basis of explanation within a certain science.

Metaphysics in this sense is of no difference from any other science. The metaphysics specificity lies only in the fact that its subject area comprises everything that exists. The basis of explanation in metaphysics is something existentially fundamental or something which grounds everything (it is possible, of course, that it coincides with everything that exists). Objections to the speculative nature of metaphysical foundations are highly biased. In any of the fundamental sciences, its explanatory basis representations are exactly to the same extent debatable and inconclusive. In physics, for example, generalizing theories serve as the basis, by which, it is supposed, all physical phenomena can be fully explained. The presence in modern physics of alternative fundamental theories, however, leaves open the question of the very possibility of such a physical theory that would explain everything in physical reality. This does not prevent physicists from formulating fundamental theories, often quite hypothetical and not based on a sufficient amount of empirical data.

Metaphysics is no different in this sense from physics, especially since it also proceeds from empirical data, although more indirectly. One can observe an increase of interest in formulat- 
ing theories, which are variants of metaphysical foundationalism in nowadays metaphysics. Metaphysical foundationalism assumes that there is the foundation (the first ground, the basis) of all that exists, that is, such a reality that conditions the existence of all other realities. The knowledge of such a reality allows, in principle, to explain everything that exists both at a whole and separately. Metaphysical foundationalism has a solid theoretical justification in modern metaphysics, which will not be discussed here (one of the ways to justify it was proposed by the author of this article [5]). Along with the rise of metaphysical foundationalism, a new impetus was given to the study of the old, already known to ancient philosophy problem - what exactly is the ground of everything, and is this foundation something one or something multiple? In other words, in modern metaphysics, the concepts of metaphysical monism and metaphysical pluralism, as well as the debate between them, get a new breath.

Metaphysical monism proceeds from the existence of one fundamental reality which grounds everything. What exactly is meant by fundamental reality is left open and opens a variety of possible findings? Different understandings of fundamental reality correspond to different versions of metaphysical monism. The biggest split is between all that exists and not all existing, in other words, between reality identified with the world itself and that which is not the world (not all but something). The identification of fundamental reality with the real world (or "concrete cosmos") deserves the name of cosmic metaphysical monism. If fundamental reality is viewed to be something different from the world itself a metaphysical conception may be called substance monism. This kind of monism models the world in which a specific fundamental substance produces all non-fundamental objects. (Ghislain Guigon defines Spinoza's Monism as a Substance Monism [2] but it is more appropriate to label it as cosmic modal monism since there is the world consisting of a unique simple substance represented by modes).

Substance monism may find its ground within the real natural world (the recollection of Thales water is the first to come on mind) that is, to be natural substance monism. Or it may find its ground outside the real natural world - that is, to be transcendent substance monism. The most vivid example of the latter is demonstrated by Neoplatonism. (Christianity complicates its metaphysical monism adopting the dogma of Trinity and drifting somewhat towards metaphysical transcendent substance pluralism).

The metaphysics of the last decades (at least analytical metaphysics) nonetheless is focused on another variant of monistic metaphysics on cosmic monism conceptions. According to them, the only fundamental object is concrete material cosmos. Such an object excludes "possibilia, abstracta, and actual concreta in categories other than object" as well as "deities and spirits" as the most prominent defender of this conception Jonathan Schaffer stresses [9]. Material cosmos includes "its planets, pebbles, particles, and other proper parts" [8]. Jonathan Schaffer calls his variant of metaphysics priority monism. The essence of this conception is expressed by Kelly Trogdon: "According to priority monism, there are many concrete entities and there is one, the cosmos, that is ontologically before all the others" [11]. Priority monism does not exclude non-fundamental objects, just setting the priority of the cosmos over them. In other words, "the priority monist holds that the cosmos is the only fundamental object, of which every other concrete object is a dependent part" [9]). The priority principle is designed to divert monistic metaphysics from what Jonathan Schaffer calls existential monism - "the view that exactly one thing exists" [8]. Existential monism, however, looks like to be out of date now. Are there still any supporters of Parmenides? All contemporary variants of cosmic monism seem to be adopting more or less the existence of non-fundamental objects or, in more general terms, - non-fundamental realities.

The modal cosmic monism of Spinoza is, by all means, priority monism. Less obvious this is in the case of the rival to Schaffer's monistic project in nowadays metaphysics - so-called austere realistic monism proposed by Terry Horgan and Matjaz Potrc [3, 7]. Its principles are these: "1. There is just one concrete particular, viz., the whole universe (the blobject); 2 . The blobject has enormous spatiotemporal structural complexity and enormous local variability - even though it does not have any genuine parts [3]. Austere realistic monism denies parts within the fundamental reality but does not deny its structural complexity. Structural het- 
erogeneity plays here the role of nonfundamental objects being diverse and differing from the homogeneous whole universe. This variant of the metaphysical cosmic monism may be called structural cosmic monism.

Jonathan Schaffer's conception is based on the whole/parts relation. The whole is the cosmos, it has parts (which include every concrete object other than cosmos) and, also, the whole is ontologically before its parts. According to mereology standards, the whole is not identical to its parts ("the cosmos is not identical to the plurality of its planets, pebbles, or particles, or any other plurality of its many proper parts" [8]). So the cosmos is the One but it has parts. Schaffer's variant of metaphysical monism may be called cosmic mereological monism.

Apart from cosmic monism, it is said about $a b$ stract monism in modern metaphysics. It is not obvious that all concreta are grounded by further concreta [10]. So a fundamental reality can be abstract and not be material cosmos. Abstract reality can coincide with the cosmos (the whole world) or not. Accordingly, we can speak about abstract cosmic monism and abstract substance monism. It is imaginable that abstract fundamental reality grounds only abstract entities [10]. But this leads to separation of abstract and concrete (material cosmic) fundamental realities, in other words, to metaphysical pluralism. Therefore abstract monism is possible only if basic abstract unique reality grounds everything including concrete material objects.

Metaphysical pluralism is a concept recognizing the existence of many (at least two) independent foundations of everything that exists. In terms of options, metaphysical pluralism is a mirror image of metaphysical monism. We can talk about cosmic pluralism and transcendent pluralism. The most consistent version of cosmic pluralism is atomism. Mirroring the conception of priority monism it is often said about priority pluralism, i. e. about "the thesis that wholes are grounded in or ontologically depend on their parts" [1]. Priority atomism is viewed to be a kind of priority pluralism, arguing that "there are multiple atoms (simple concreta)..., and any complex concrete entity decomposes into atoms such that the latter ground the former" [10]. The substitution of priority monism by mereological monism de- mands the same transformation of the term "priority pluralism". So it seems more accurate to say about mereological pluralism and its atomistic variant. There is one more variant of mereological pluralism mentioned in metaphysical papers which is close to atomism - according to it "the basic concreta are space-time points" [4], not material atoms.

This article's objective is to make it clear that all discussed variants of monism and pluralism are unsatisfactory from their claims to express the explanatory basis of metaphysics. It will be shown that some more thoroughly reasoned conception is possible, which, being generally monistic, does not exclude pluralism and which could be called in this context super-monism. It will be argued that the object of this theoretic construction, the fundamental world reality, expressed by minimal conceptual means, makes a formula, consecutive application of which should allow us to describe at an extremely abstract level everything that exists.

\section{RESULTS AND DISCUSSION}

Metaphysical pluralism is not a working conception. Two cases are possible while implementing this idea.

A) Basic realities (metaphysical atoms) are independent of each other. Then they are the real basis of everything. But complete independence means non-coexistence. For example, if you imagine the world that is completely, absolutely, in any sense disconnected with our world, then neither part of this outer world do exist for our world. Our world is all that exists and this is so just because we define the World as all that exists. (We are not talking about hypothetical other physical universes. Since they are physical, they are not completely unrelated to our physical universe, in a sense they are similar to our physical world). It does not seem possible that there coexist objects that are derived from mutually independent primary fundamental objects. The independence of fundamental realities must also be preserved in the entities grounded by them, otherwise, any of the fundamental realities is not independent, since it allows something in common with other fundamental realities (common products or consequences). Thus, the world as everything existing cannot be based on multiple independent entities. 
B) Suppose that basic realities are interconnected and interdependent. Then they are not basic realities. They have something in common, which is a necessary condition for their existence. This common part or aspect of basic realities is different from each of the assumed basic realities, otherwise (if it coincides with one of them) we do not have basic realities, but the unique fundamental object and realities derived from it. A common reality, which differs from all assumed basic realities, is an obvious condition for their existence, while the existence of each of the basic realities is not a condition for the existence of a common reality as such (it would exist in a case when any of the basic realities is subtracted, including even the situation in which there are only two realities). Thus, the common reality that we singled out is the actual primary ground of everything, and the alleged basic realities already mentioned are not basic.

Undoubtedly, metaphysical monism is a working conception for explaining everything that exists. Monism, however, requires clarification and resolution of a number of the problems it creates. Concrete monism does not work, that is, the recognition of a concrete object as the ground of the whole world. First of all, we need to keep in mind cosmic monism, equally mereological and non-mereological, as well as substance monism - theological or not. Cosmos as a concrete whole has a set of specific properties (which are parts of the cosmos as it appears in mereological monism, and space-time inhomogeneities in non-mereological monism). Each specific property is not fundamental (this follows from what has been said about metaphysical pluralism). Moreover, their combination is not fundamental (for the same reason). Cosmos in the holistic concept of J. Schaffer is something more than a collection of parts. If this super-partial reality depends on parts of the cosmos, it is not fundamental. If it does not, it is a special reality, and it is fundamental, but not specifically cosmic.

Monism arising from the idea of super-cosmic reality inevitably turns out to be transcendent monism. It is consistent with religion, although it does not necessarily have religious content. It is irrational, therefore unscientific. As an option for explaining our world, it has the right to exist and can be true (one may agree that science does not have a monopoly on truth), but it needs convincing evidence while we have none for the time being. Here it is not a subject of reflection, we are talking about the possibilities of scientific metaphysics.

If one insists on the coincidence of the fundamental ground of everything that exists with the world in which we find ourselves, then cosmic monism turns out to be nothing more than existential monism. The world as a fundamental reality should be one thing, without any parts, structures, and heterogeneities. Given that: 1) abstract objects are determined by qualitative scarcity, having fewer attributes compared to concrete objects; and 2) the only attribute that unites everything in the world is existence (this follows from the definition of the world as "everything existing"), the world must be conceived as an extremely abstract object. Such an object, at the same time, stands as an ultimate abstract object to a diverse concrete cosmos. Existential monism, in this perspective, is the final case of abstract monism. Any other abstract monism (emanating from abstractions of non-ultimate, non-terminal levels, for example, from mathematical sets) loses, similarly to concrete cosmic monism, its fundamental character.

Existential abstract monism is incontrovertible from its being grounded (as that which needs no grounding). The foundation of everything is recognized as the world and identically as everything existing, so the only attribute of the world is its existence. All that exists in the world. The World and the Existing happen to be the same. In such an object, the property coincides with what has this property, completely dissolves in it. The existing is the same as existence. Existence is existing. (This unity of existence and the existing can be expressed by the term "being"). There is no need to ground such a foundation. After all, grounding something, we find the justification for its existence. But what could be the ground of existence itself? Why does existence exist? Because it is existence. It has the ground of its existence in itself, or rather, it does not require any ground. The question of some ground for existence outside existence is illogical and meaningless. Note that this principle causa sui applies only to existence and not do anything more.

On the other hand, existential abstract monism looks completely helpless from its grounding power (as that which grounds). Nothing can be deduced from pure being in itself. Peering into 
pure being a metaphysician feels like having no chances to make it clear where all the diversity of the world comes from. We cannot follow Hegel and build the world on the dialectic of pure being and nothing. Nothing (absolute nonexistence) does not exist in any sense (unlike relative non-existence - the non-existence of something, non-existence somewhere, or sometimes). Therefore, nothing has nothing to do with being, even as a negation (to be a negation something must exist in some sense, which does not apply to absolute non-existence). All that we have is being (existence indistinguishable from the existing). Being in itself is not followed by anything - both logically and naturally. This is the initial problem of metaphysical foundationalism.

The world which metaphysicians talk about is both complex and simple. The world is all that exists, and therefore it is something plural, an aggregate of entities. At the same time, the world is one thing and in this sense the monistic idea of the world is true. In order not to confuse the two meanings of the term "world", we will call the world as multiplicity the cosmos (the world-cosmos), and the world as something one being (the world-being). The worldcosmos completely coincides with the worldbeing. It is also obvious that these two terms refer to different realities. One is many, but one cannot be many. Note that we are talking about extreme abstractions, therefore, there is no resolution of the contradiction by assigning the identity of concepts to their extension, and the difference to their intensions. The contradiction is insoluble. Let's fixate this position.

A contradiction is a logical state of affairs, which usually indicates the falsity of one of the conflicting statements. Therefore, the first possible consequence of the contradiction mentioned here is to admit the falsity of monistic conception and return to pluralism (which, as has been shown, is also false). Another possible solution is to recognize the inapplicability of logic itself for the position we have fixed. Logic is, in fact, a set of the most abstract links of any existing objects normalized and expressed in terms. One may assume that the foundation of reality is outside the action of the laws of logic (in any case, outside of what is commonly accepted as logic).

The reason for this is that within the foundation of reality the concept of a link is irrelevant.
The foundation of reality lies before all connections and relations that should only arise along with realities derived from the foundation. There are no connections of objects - there is no logic - there are no laws of logic - there is no law of contradiction. "Something (the worldbeing) is something else (the world-cosmos)" and "something (the world-being) is only itself and not the other (the world-cosmos)" are completely compatible statements. Both express reality - the same reality and not the same reality. Note that we are not talking about the connection of objects, we are only talking about their direct, immediate, and complete identity and the same difference.

This denying the traditional logic manner of reasoning is similar to Hegel's dialectical logic. But, firstly, as already noted, the concept of nothing (absolute non-existence) does not apply here. Secondly, it is not going about being out of itself or being-other (Anderssein). The basic principle of dialectical logic: something is itself and is something else, another posits itself as the being-other of the previous object (or a concept in Hegel's word). In developed form, being-other is a negation of the previous reality (going through the stages of difference, opposition, contradiction, and reaching negation). It looks like this is too complex a construction, characteristic rather of thinking, but not of being. Being is simpler than that. It is extremely simple. In being, everything is limited to identity and difference only. Something is identical to itself. Something is different from another. Something is identical to another. Being identical to another, something is not something being out of itself. It is just identical to another (in some sense) but is not lost in another. The identity to another is preserved along with the identity to itself. The difference from another is preserved along with the difference from one's own identity with another. Something does not differ from itself, but differs from itself, being identical to another, that is, differs always from another (not from itself). In these provisions, all prelogical (from generally accepted formal logic) reality is expressed.

Being which is identical with itself can be called simply identity. Being is not different from identity, identity in itself (not the identity of something, but pure identity) is identical to being. Being which is different from identity (and from itself as an identity) is identical to difference. Being is different from the difference. The 
difference is identical to being and differs from it. In the same way, the difference is identical to the difference and identical to identity. The difference is different from identity and different from the difference that is identical to identity. Being as the difference can be identified with existence. Being an identity can be identified with the existing. Being is a difference, identity, the existing, existence. This is the same, therefore we can talk about a single world reality, which underlies everything. This idea of a single reality is metaphysical monism (abstract and existential). On the other hand, there is diversity in this one reality, because this one reality is a difference. One can argue that the fundamental ground of all that exists is a pure difference, taking into account that difference is identical with being or identical with the world-being, the world as one. The ground of everything is an abstract self-identical object difference (diversity). So far, this diversity is extremely limited and extremely abstract. But it contains the basis for branching into the diverse cosmos.

The difference is different and identical to itself. Taken in this aspect, it turns out to be the existing (is identical to the existing). Otherwise, it can be expressed this way: the existing is the difference (is identical to difference). The difference is the difference between something and something else. Since that which is different is also something existing, there is the object $A$, which is different, the object $B$, from which the object $A$ is different, the object $C$, which is identical to the difference of the object A from the object $B$. If the task of metaphysics is to determine the entire diversity of things, then this can be done on the ground that all things are identical to a difference between entities (or objects) that differ from them. Formally this is expressed as " $\mathrm{C}$ is identical to the difference of A from B". The metaphysical super-monism which is described here gives reason to assert that any object (defined as that which exists and is identical to itself and differs from everything else) is determined by the formula expressed above (it can be called the basic formula of metaphysics). Repeating this formula infinitely, one can describe the whole world at an extremely abstract (metaphysical) level, embracing everything that exists in one way or another (in any sense of the word). A metaphysical system, in this case, is reduced to unlimited repetition (iteration) of one formula. The format of the article does not allow us to present the result of such a metaphysical description of the world. The result (however vastly far from even relatively complete) can be found in the book [6].

\section{CONCLUSION}

The content of the article can be reduced to such basic statements.

Metaphysics (as the science of the existing or of the world as a whole), like other sciences, is focused on the description of its subject - the totality of existing, the world as a whole - as fully as possible and by minimal means. This task is performed by metaphysical fundamentalism, recognition of the fundamental ground of everything that exists, which is the ultimate foundation in the chain of objects grounding. The two possible forms of fundamentalism are metaphysical pluralism and metaphysical monism, modern versions of which are analyzed in the article. Theoretical reflection shows the implausibility of pluralism and its inefficiency in solving the problems of metaphysics. As for metaphysical monism, it is appropriate to agree with both its absolute validity and the need for clarification as a grounding force. An understanding of monism is proposed based on the logic of fundamental reality which differs from generally accepted formal logic in that it lacks logical laws, primarily the law of contradiction. The fundamental reality is defined as pure being which is identical with a difference, identity, existence, and the existing. By the identification of the various, this reality is defined as one. By identity with distinction, this reality is defined as the ground of all world diversity. Being which is expressed in terms of difference and identity is reflected in the metaphysical formula, which is proposed as the only tool for describing everything that exists at the extremely abstract level. 


\section{REFERENCES}

1. Bailey, A. M. (2011). The incompatibility of composition as identity, priority pluralism, and irreflexive grounding. Analytic Philosophy, 52 (3), 171-174. doi: 10.1111/j.2153960X.2011.00525.X

2. Guigon, G. (2012). Spinoza on Composition and Priority. In G. Philip (Ed.), Spinoza on Monism (pp. 183-205). New York: Palgrave-Macmillan.

3. Horgan, T., Potrč, M. (2000). Blobjectivism and indirect correspondence. Facta Philosophica, 2 (2), 249-270.

4. Kriegel, U. (2012). Kantian Monism. Philosophical Papers, 41(1), 23-56. doi: 10.1080/05568641.2012.662806

5. Kulieshov, A. (2016). Metaphysical Foundationalism: a New Form of Justification. Path of Science, 2(12), 3.1-3.9. doi: 10.22178/pos.17-3

6. Kulieshov, A. (2019). Nachala metafiziki [The foundations of metaphysics]. Stavropol: Logos (in Russian) [Кулешов, А. (2019). Начала метафизики. Ставрополь: Логос].

7. Potrč, M., \& Strahovnik, V. (2019). Ontological Reflections on What There Is. Open Journal of Philosophy, 09(02), 140-151. doi: 10.4236/ojpp.2019.92010

8. Schaffer, J. (2009). Monism: The Priority of the Whole. Philosophical Review, 119(1), 31-76. doi: 10.1215/00318108-2009-025

9. Tahko, T. E., O'Conaill, D. (2012). On the Common Sense Argument for Monism. In Philip Goff (ed.), Spinoza On Monism. (pp. 149-166). Palgrave-Macmillan.

10. Trogdon, K. (2017). Priority monism. Philosophy Compass, 12(11), e12458. doi: $10.1111 /$ phc3.12458

11. Trogdon, K., \& Cowling, S. (2018). Prioritizing Platonism. Philosophical Studies, 176(8), 2029-2042. doi: 10.1007/s11098-018-1109-4 